\title{
PENGARUH PENGGUNAAN NESTING TERHADAP PERUBAHAN SUHU TUBUH SATURASI OKSIGEN DAN FREKUENSI NADI PADA BAYI BERAT BADAN LAHIR RENDAH DI KOTA CIREBON
}

\author{
Nanang Saprudin, Isti Kumala Sari \\ Program Studi S1 Keperawatan STIKes Kuningan \\ ayyumna1985@yahoo.com
}

\begin{abstract}
Abstrak
Bayi berat lahir rendah di Indonesia masih tergolong tinggi dan masih menjadi perhatian serius. BBLR mengakibatkan gangguan fungsi vital organ yang berakhir pada penurunan kualitas proses pertumbuhan dan perkembangan anak. Penanganan BBLR yang dianjurkan adalah penggunaan nesting. Penelitian ini bertujuan untuk mengetahui pengaruh penggunaan nesting terhadap perubahan suhu tubuh, saturasi oksigen dan frekuensi nadi bayi berat lahir rendah.

Penelitian ini menggunakan metode kuantitatif dengan quasi eksperimen dengan rancangan nonequivalent control group design dengan menggunakan one group pretest posttest. Subjek penelitian ini adalah BBLR sesuai kriteria. Teknik pengambilan sampel dengan purposive sampling sebanyak 40 responden. Instrumen yang digunakan adalah lembar observasi, termometer dan probe finger oxymetri yang telah dikalibrasi. Analisis yang digunakan adalah uji beda dengan dependent t tes.

Hasil penelitian menunjukan terdapat peningkatan rerata suhu tubuh, saturasi oksigen dan frekuensi nadi pada BBLR setelah penggunaan nesting. Hasil penelitian terdapat perbedaan suhu tubuh, saturasi oksigen dan frekuensi nadi pada BBLR dengan masing masing $\mathrm{p}$ value $<0,05$.

Simpulan dari penelitian ini terdapat pengaruh nesting terhadap suhu tubuh, saturasi oksigen dan frekuensi nadi pada BBLR. Disarankan bagi perawat untuk melaksanakan penggunaan nesting secara berkelanjutan pada BBLR diruangan agar pemulihan dan kestabilan tanda vital bayi BBLR bisa dilaksanakan dengan tepat dan cepat.
\end{abstract}

Kata Kunci : Nesting, Suhu, Saturasi, Nadi, BBLR

\section{Pendahuluan}

Bayi berat lahir rendah mengalami kesulitan dalam beradaptasi dan melakukan pertahanan yang kuat dengan ekstra uteri setelah lahir. Hal ini disebabkan karena imaturnya sistem organ tubuh bayi seperti paru-paru, ginjal, jantung, imun tubuh serta sistem pencernaan (Deswita, 2010). Sulitnya bayi berat lahir rendah beradaptasi dengan lingkungan dan rentan terkena stres menjadi faktor resiko kesakitan dan kematian (Syahreni, 2010). Ketidakstabilan respon fisiologis bayi berat lahir rendah menyebabkan bayi memiliki faktor resiko tinggi terkena penyakit komplikasi seperti asfiksia, bradikardi, penyakit paru kronis, hiperbilirubinemia, kejang, distres pernapasan, hipoglikemia, transient hypothyroxinemia (Perlman, 2001 dalam Syahreni, 2010).

Bayi berat lahir rendah juga sangat rentan terjadi hipotermi dikarenakan tipisnya cadangan lemak di bawah kulit dan 
masih belum matangnya pusat pengatur panas di otak (Zaviera, 2008). Kondisi hipotermi tersebut menyebabkan perubahan sistem saraf pusat permanen hingga akhirnya menyebabkan mortalitas. Bayi yang kedinginan menghabiskan kalori untuk menghangatkan tubuh dan sebaliknya melakukan upaya untuk menstabilkan suhu tubuh hingga normal. Kondisi hipotermi menyebabkan konsumsi oksigen meningkat dan apabila tidak terpenuhi menyebabkan situasi hipoksia dan menimbulkan takikardi atau bradikardi sebagai respon terhadap penurunan oksigenasi (Wilkinson \& Green, 2012).

Kelahiran dengan berat lahir rendah masih merupakan permasalahan dunia hingga saat ini karena merupakan salah satu penyebab kematian bayi baru lahir (Sloan et al., 2008). Angka Kematian Bayi (AKB) di Indonesia masih tinggi dibandingkan negara berkembang lainnya (BPS, 2013). Secara nasional angka bayi berat lahir rendah secara keseluruhan sebanyak 7,5\% (SDKI, 2012). Sementara angka kematian bayi diCirebon menurut data Profil Kesehatan Propinsi Jawa Barat adalah 51 per 4,803 kematian bayi. Jumlah bayi berat lahir rendah yang dirawat selama tiga bulan terakhir (Januari - Maret 2017) didapatkan data sebanyak 106, dengan berat lahir $\leq$ 2000 gram sebanyak 61 bayi (Medical Record, 2017). Berbagai upaya telah dilakukan untuk menurunkan Angka Kematian Bayi dan meminimalkan dampak negatif yang ditimbulkan selama perawatan. Salah satunya dengan menerapkan developmental care atau asuhan perkembangan. Prinsip-prinsip developmental care meliputi keterlibatan keluarga, posisi dan pemberian nesting, perawatan kulit, meminimalkan stres dan nyeri, mengoptimalkan nutrisi, dan meningkatkan kualitas tidur (Altimier,2011). Beberapa penelitian telah membuktikan bahwa developmental care telah berhasil membantu bayi berat lahir rendah melewati proses perawatan dan dapat pulang dalam kondisi yang sehat.
Pemasangan nesting atau sarang merupakan salah satu metode pengelolaan lingkungan dalam developmental care. Beberapa penelitian tentang manfaat nesting telah dilakukan didalam maupun diluar negeri. Penelitian oleh Bayuningsih (2011) menunjukkan bahwa penggunaan nesting dan posisi prone efektif mempengaruhi saturasi oksigen dengan $\mathrm{p}<$ $\alpha$, sedangkan menurut Wilawan, Patcharee \& Chavee (2009) menyebutkan bahwa posisi prone sangat mempengaruhi perbaikan saturasi oksigen, pengembangan paru, pengembangan dinding dada dan penurunan insiden apnea pada bayi prematur.

Berdasarkan wawancara dengan perawat Ruang Perinatologi RSD Gunung Jati Kota Cirebon, didapatkan informasi bahwa penggunaan nesting telah dilakukan pada bayi berat lahir rendah dengan berat lahir $\leq 2000$ gram, meskipun hal tersebut belum ditetapkan dalam Standar Prosedur Operasional rumah sakit. Anjuran penggunaan nesting didapatkan berdasarkan hasil pelatihan dan baru dilakukan dalam tiga bulan terakhir. Pada kurun waktu 3 bulan tersebut, $100 \%$ bayi dengan berat lahir rendah yang dirawat berhasil melewati proses perawatan sehingga pulang dengan kondisi fisiologis yang sehat, dimana pada periode sebelumnya bayi dengan berat lahir kurang dari 2000 gram sulit mencapai fase ini.

Berdasarkan fenomena diatas serta belum adanya penelitian serupa tentang penggunaan nesting pada bayi dengan berat lahir rendah, oleh karena itu peneliti tertarik untuk melakukan penelitian lanjut tentang " Pengaruh Penggunaan Nesting Terhadap Perubahan Suhu Tubuh, Saturasi Oksigen dan Frekuensi Nadi Pada Bayi Berat Lahir Rendah di RSD Gunung Jati Kota Cirebon",

\section{Metode}

Jenis penelitian yang digunakan adalah penelitian quasi eksperimen dengan rancangan nonequivalent control group 
JURNAL ILMU KESEHATAN BHAKTI HUSADA:

HeAlth SCIENCES JournaL, Vol. 09 No. 02, DESEMBER 2018

DOI: https://doi.org/10.34305/jikbh.v9i2.63

design dengan menggunakan one group pretest posttest. Desain ini tidak memiliki kelompok pembanding (kontrol), tetapi setidaknya telah dilakukan observasi pertama (pretest) yang memungkinkan menguji perubahan yang terjadi setelah dilakukan eksperimen meskipun tidak ada jaminan bahwa perubahan yang terjadi pada variabel dependen karena intervensi atau perlakuan.

Populasi pada penelitian ini adalah seluruh BBLR yang dirawat di Ruang Perinatalogi RSD Gunung Jati Kota Cirebon. Sampel diambil sebanyak 40 responden sesuai dengan kriteria. Teknik sampling yang digunakan adalah purposive sampling.

Kriteria inklusi sampel pada penelitian ini: Apgar skor 4/6 - 7/8, Berat badan bayi $\geq 1500$ - 2500 gram, Keluarga bersedia menjadi responden penelitian. Sedangkan kriteria ekslusinya adalah : Tidak dalam keadaan asfiksia sedang berat, Tidak dalam kedaan foto terapi.

Variabel yang diteliti meliputi variabel bebas dan terikat. Variabel bebasnya adalah penggunaan nesting. Variabel terikatnya adalah suhu, saturasi oksigen dan frekuensi nadi bayi berat lahir rendah. Instrumen penelitian yang digunakan berupa kuisioner data demografi, lembar observasi untuk mencatat karakteristik dan hasil penelitian, kain, termometer digital axilla dan Probe finger oxymetry dari Bedside Monitor yang sudah dikalibarsi sebelumnya digunakan sebagai alat pemeriksaan.

Analisis data dilakukan secara dua tahap yaitu analisis univariat dan analisis bivariat. Analisis univariat menggunakan tendensi sentral sedangkan analisis bivariat menggunakan uji $\mathrm{t}$ dependen setelah dilakukan uji normalitas data. Penelitian ini dilakukan di ruang perinatologi RSD Gunung Jati Kota Cirebon. Penelitian ini dilaksanakan pada Bulan Juni - Juli 2018.
Pengambilan sampel dilakukan berdasarkan kriteria yang telah ditentukan oleh peneliti. Teknik pengambilan ada perubahan yang pada awalnya accidental sampling menjadi purposive sampling sesuai dengan pertimbangan peneliti. Sampel diambil sebanyak 40 responden berdasarkan kriteria. Sebelumnya peneliti melakukan informed consent pada keluarga sebelum diberikan perlakuan. Sebelum perlakuan, terlebih dahulu peneliti menilai suhu, saturasi oksigen dan frekuensi nadi dan mencatat hasil dalam lembar observasi. Penggunaan nesting diberikan selama 30 menit dan setelahnya, bayi dikur kembali suhu, saturasi oksigen dan frekuensi nadinya. Data yang sudah terkumpul kemudian dilanjutkan dengan pengolahan yang selanjutnya dilakukan analisis baik secara univariat dan bivariat sesuai dengan tujuan penelitian. Uji yang digunakan menggunakan uji $t$ dependen karena distribusi datanya normal.

\section{Hasil Penelitian}

Penelitian ini berlangsung selama kurang lebih dua bulan mulai dari bulan Juni - Juli tahun 2018 di ruang perinatologi RSD Gunung Jati Kota Cirebon. Sampel diambil secara accidental sampling berdasarkan kriteria yang telah ditetapkan sebelumnya oleh peneliti. Sampel penelitian sebanyak 40 responden dengan menilai suhu tubuh, saturasi oksigen serta frekunsi nadi BBLR. Hasil penelitian diuji analisis baik secara univariat maupun bivariat. Analisis univariat menggunakan tendensi sentral serta uji bivariat menggunakan uji $t$ dependen sehubungan dengan data berdistribusi normal. Hasil penelitian ini juga dilengkapi dengan karakteristik responden yang mencakup jenis kelamin, derajat asfiksia dan Berat Badan Saat Penelitian. Berikut ini hasil penelitian yang disajikan dalam bentuk tabel sebagai berikut: 


\section{Tabel 5.1. Distribusi Karakteristik Responden Berdasarkan Jenis Kelamin di Ruang Perinatologi RSD Gunung Jati Kota Cirebon 2018}

\begin{tabular}{lll}
\hline Jenis Kelamin & Jumlah & Persentase \\
\hline Laki - Laki & 24 & 60 \\
Perempuan & 16 & 40 \\
\hline
\end{tabular}

Sumber : Data Primer 2018

Tabel 5.2 Gambaran Rerata Berat Badan Responden di Ruang Perinatologi RSD Gunung Jati Kota Cirebon $2018(n=40)$

\begin{tabular}{llllll}
\hline Variabel & Rerata & Median & SD & Min & Maks \\
\hline Berat Badan & 2061,50 & 2100 & 299,77 & 1500 & 2450 \\
\hline
\end{tabular}

Sumber : Data Primer 2018

Hasil penelitian menunjukan bahwa rerata berat badan responden 2061,5 gram dengan nilai median 2100 gram, Standar deviasinya
299,77 dan nilai minimum 1500 gram dan nilai maksimum berat badan 2450 gram.

Tabel 5.3 Rerata Suhu Tubuh, Saturasi Oksigen dan Frekuensi Nadi Responden sebelum dan sesuadah penggunaan nesting di Ruang Perinatologi RSD Gunung Jati Kota Cirebon 2018 (n=40)

\begin{tabular}{llllll}
\hline Variabel & Rerata & Median & SD & Min & Maks \\
\hline Suhu Tubuh (Sebelum) & 36,3 & 36,3 & 0,349 & 35,5 & 37,1 \\
Suhu Tubuh (Sesudah) & 36,8 & 36,9 & 0,268 & 36,3 & 37,4 \\
Saturasi Oksigen (Sebelum) & 92 & 92,5 & 2,453 & 88 & 97 \\
Saturasi Oksigen (Sesudah) & 95 & 96 & 1,746 & 93 & 99 \\
Frekuensi Nadi (Sebelum) & 130 & 129,5 & 8,092 & 117 & 147 \\
Frekunesi Nadi (Sesudah) & 143 & 144 & 7,793 & 126 & 156 \\
\hline
\end{tabular}

Sumber : Data Primer 2018

Hasil penelitian menunjukan bahwa rerata suhu tubuh responden sebelum diberikan nesting yaitu $36,3^{\circ} \mathrm{C}$ dengan nilai median $36,3^{\circ} \mathrm{C}$ dan standar deviasi 0,349 serta nilai minimal $35,5^{\circ} \mathrm{C}$ dan nilai maksimal $37,1^{\circ} \mathrm{C}$. Setelah diberikan nesting rerata suhu menjadi $36,8^{\circ} \mathrm{C}$ yang artinya ada peningkatan sebesar $0,5^{\circ} \mathrm{C}$. Begitupula dengan nilai median, suhu responden menjadi $36,9^{\circ} \mathrm{C}$ dan standar deviasi menjadi 0,268 . Setelah diberikan nesting nilai minimal suhu $36,3^{\circ} \mathrm{C}$ dan nilai maksimal suhu $37,4^{\circ} \mathrm{C}$.

Sedangkan dilihat dari saturasi oksigen, rerata saturasi oksigen sebelum diberikan nesting yaitu $92 \%$ dengan nilai median 92,5 \% dan standar deviasi 2,453 serta nilai minimal $88 \%$ dan nilai maksimal $97 \%$. Setelah diberikan nesting rerata saturasi oksigen menjadi $95 \%$ yang artinya ada peningkatan sebesar $3 \%$. Begitupula dengan nilai median, saturasi oksigen responden menjadi $96 \%$ dan standar deviasi menjadi 1,746. Setelah diberikan nesting nilai minimal saturasi oksigen $93 \%$ dan nilai maksimal saturasi oksigen $99 \%$.

Sedangkan dilihat dari frekuensi nadi, rerata frekuensi nadi sebelum diberikan nesting yaitu $130 \mathrm{x} /$ menit dengan nilai median 129,5 x/menit dan standar deviasi 8,092 serta nilai minimal 117 $\mathrm{x} /$ menit dan nilai maksimal $147 \mathrm{x} /$ menit. 
Setelah diberikan nesting rerata frekunesi nadi menjadi $143 \mathrm{x} /$ menit yang artinya ada peningkatan sebesar $13 \mathrm{x} /$ menit. Begitupula dengan nilai median, frekuensi nadi responden menjadi $144 \mathrm{x} /$ menit dan standar deviasi menjadi 7,793. Setelah diberikan nesting nilai minimal frekunsi nadi 126 $\mathrm{x} / \mathrm{menit}$ dan nilai maksimal frekuensi nadi 156 $\mathrm{x} / \mathrm{menit}$.

\section{Tabel 5.4}

Hasil Uji Normalitas Data Suhu Tubuh, Saturasi Oksigen dan Frekuensi Nadi Responden Sebelum dan setelah Penggunaan Nesting Di Ruang Perinatalogi RSD Gunung Jati Kota Cirebon Tahun $2018(n=40)$

\begin{tabular}{lccc}
\hline \multicolumn{1}{c}{ Variabel } & Shapiro - Wilk & & \\
\cline { 2 - 4 } \multicolumn{1}{c}{ Statistik } & Df & Sig \\
\hline Suhu Tubuh (Sebelum) & .971 & 40 & .400 \\
Suhu Tubuh (Sesudah) & .973 & 40 & .435 \\
Saturasi Oksigen (Sebelum) & .948 & 40 & .065 \\
Saturasi Oksigen (Sesudah) & .940 & 40 & .034 \\
Frekuensi Nadi (Sebelum) & .943 & 40 & .043 \\
Frekuensi Nadi (Sesudah) & .969 & 40 & .335 \\
\hline
\end{tabular}

Sumber : Data Primer 2018

Hasil penelitian menunjukan bahwa nilai probabilitas berdasarkan uji ShapiroWilk > 0,05 artinya data berdistribusi normal. Pada penelitian ini, uji bivariat yang tepat yaitu menggunakan uji $t$ dependen.

Tabel 5.5

Perbedaan Suhu Tubuh Responden Sebelum dan Setelah Penggunaan Nesting Di Ruang Perinatalogi RSD Gunung Jati Kota Cirebon Tahun 2018 (n=40)

\begin{tabular}{ccccc}
\hline Variabel & Fase & Mean & SD & p value \\
\hline Suhu Tubuh & Sebelum & 36,3 & 0,349 & 0,000 \\
& Sesudah & 36,8 & 0,268 & \\
\hline
\end{tabular}

Sumber : Data Primer 2018

Hasil penelitian menunjukan bahwa rerata suhu tubuh responden sebelum diberikan nesting yaitu $36,3^{\circ} \mathrm{C}$ dan menjadi $36,8^{\circ} \mathrm{C}$ setelah diberikan nesting. Artinya terjadi peningkatan suhu sebesar $0,5^{\circ} \mathrm{C}$. Hasil uji statistik didapat $\mathrm{p}$ value $0,000<\alpha$ $(0,05)$, oleh karena itu bisa disimpulkan terdapat perbedaan suhu tubuh responden sebelum dan setelah penggunaan nesting di ruang perinatalogi RSD Gunung Jati Kota Cirebon. Dengan kata lain, hasil penelitian ini membuktikan adanya pengaruh pemberian nesting terhadap suhu tubuh bayi BBLR.

Tabel 5.6

Perbedaan Saturasi Oksigen Responden sebelum dan Setelah Penggunaan Nesting Di Ruang Perinatalogi RSD Gunung Jati Kota Cirebon Tahun 2018 (n=40)

\begin{tabular}{llccc}
\hline Variabel & Fase & Mean & SD & p value \\
\hline Saturasi & Sebelum & 92 & 2,453 & 0,000 \\
Oksigen & Sesudah & 95 & 1,746 & \\
\hline
\end{tabular}

Sumber : Data Primer 2018 
Hasil penelitian menunjukan bahwa rerata saturasi oksigen responden sebelum diberikan nesting yaitu $92 \%$ dan menjadi $95 \%$ setelah diberikan nesting. Artinya terjadi peningkatan saturasi oksigen sebesar $3 \%$. Hasil uji statistik didapat $\mathrm{p}$ value $0,000<\alpha(0,05)$, oleh karena itu bisa disimpulkan terdapat perbedaan saturasi oksigen responden sebelum dan setelah penggunaan nesting di ruang perinatalogi RSD Gunung Jati Kota Cirebon. Dengan kata lain, hasil penelitian ini membuktikan adanya pengaruh pemberian nesting terhadap saturasi oksigen bayi BBLR.

Tabel 5.7

Perbedaan Frekuensi Nadi Responden sebelum dan Setelah Penggunaan Nesting Di Ruang Perinatalogi RSD Gunung Jati Kota Cirebon Tahun $2018(n=40)$

\begin{tabular}{lcccc}
\hline \multicolumn{1}{c}{ Variabel } & Fase & Mean & SD & p value \\
\hline Frekuensi & Sebelum & 130 & 8,092 & 0,000 \\
Nadi & Sesudah & 143 & 7,793 & \\
\hline
\end{tabular}

Sumber : Data Primer 2018

Hasil penelitian menunjukan bahwa rerata frekuensi nadi responden sebelum diberikan nesting yaitu $130 \mathrm{x} /$ menit dan menjadi $143 \mathrm{x} / \mathrm{menit}$ setelah diberikan nesting. Artinya terjadi peningkatan frekuensi nadi sebesar $13 \mathrm{x} /$ menit. Hasil uji statistik didapat $\mathrm{p}$ value $0,000<\alpha(0,05)$, oleh karena itu bisa disimpulkan terdapat perbedaan frekuensi nadi responden sebelum dan setelah penggunaan nesting di ruang perinatalogi RSD Gunung Jati Kota Cirebon. Dengan kata lain, hasil penelitian ini membuktikan adanya pengaruh pemberian nesting terhadap frekuensi nadi bayi BBLR.

\section{Pembahasan}

Hasil penelitian ini membatasi pada pengaruh nesting terhadap perubahan suhu tubuh, frekuensi nadi dan saturasi oksigen BBLR. Hasil penelitian membuktikan terdapat perbedaan suhu tubuh, frekuensi nadi dan saturasi oksigen BBLR sebelum dan sesudah penggunaan nesting. Pembahasan penelitian ini didukung oleh beberapa sumber berdasarkan teori dan jurnal terkait. Hasil pembahasan penelitian dijelaskan sebagai berikut :

\section{Gambaran Rerata Suhu Tubuh, Saturasi Oksigen dan Frekuensi Nadi BBLR sebelum dan sesudah penggunaan nesting di Ruang Perinatologi RSUD Gunung Jati Kota Cirebon Tahun 2018}

Hasil penelitian menunjukan bahwa rerata suhu tubuh responden $36,3^{\circ} \mathrm{C}$. Kondisi ini menunjukan bahwa responden mengalami penurunan suhu tubuh atau hipotermia. Suhu tubuh normal pada neonatus berkisar antara $36,5{ }^{\circ} \mathrm{C}-37,5^{\circ} \mathrm{C}$ (Saifudin dkk, 2009). Hipotermia dikarenakan responden terlahir dalam keadaan berat badan lahir rendah. Kondisi BBLR pada umumnya dicirikan dengan belum sempurnanya fungsi organ seperti fungsi termoregulasi, rendahnya lemak subkutan, permukaan kulit yang tipis dan transparan serta luasnya permukaan tubuh yang lebih besar dari masa. Selain faktor tersebut, kondisi lainnya yang mempengaruhi terjadinya hipotermi adalah rendahnya kemampuan BBLR dalam mengatur produksi dan pelepasan panas. Menurut Perinasia (2003), mekanisme pengeluaran panas terdiri dari proses radiasi, konveksi, evaporasi serta konduksi.

Hal ini didukung oleh penelitian Miller, Lee \& Gould (2011) dikatakan bahwa hipotermia banyak terjadi pada BBLR yang berujung pada kematian 
neonatus. Oleh karenanya penting untuk menjaga dan mempertahankan suhu lingkungan yang hangat pada neonatus. Berbicara tentang mekanisme pelepasan kalor, peneliti juga menemukan beberapa kondisi evaporasi dan konveksi yang terjadi pada beberapa responden sehingga meningkatkan potensi hipotermi. Hasil observasi peneliti ditemukan adanya keterlambatan dalam penggantian popok yang basah yang terjadi pada beberapa responden. Hal ini tentunya dapat meningkatkan pengeluaran panas atau proses evaporasi. Selain itu, ada juga peningkatan proses konveksi yang ditunjukan dengan terpaparnya responden oleh pintu yang terbuka atau jarak pendingin ruangan yang berdekatan.

Hasil penelitian juga menunjukan adanya peningkatan suhu sebesar $0,5^{\circ} \mathrm{C}$ pada rerata suhu responden setelah pemberian nesting. Hasil penelitian menunjukan rerata suhu tubuh responden setelah penggunaan nesting yaitu $36,8^{\circ} \mathrm{C}$. Hal ini menandakan responden berada dalam kisaran suhu tubuh yang normal. Penggunaan nesting selama 30 menit mampu meningkatkan suhu tubuh responden meskipun tidak terlalu signifikan. Peneliti berpendapat karena dengan menggunakan nesting mampu memfasilitasi responden untuk kembali pada posisi fleksi. Posisi ini meningkatkan kemampuan responden untuk mempertahankan posisi fleksi seperti adduksi bahu dan siku, pinggul dan lutut fleksi dan kepala berada digaris tengah. Bayi juga lebih mudah dalam menggerakan anggota gerak atas ke mulut atau gerakan tangan. Nesting berguna untuk menopang tubuh bayi dan juga memberikan tempat yang nyaman. Hal ini juga didukung oleh Wong et all (2009), yang menjelaskan bahwa melalui posisi fleksi, bayi difasilitasi untuk meningkatkan aktivitas tangan ke mulut dan tangan menggenggam. Kondisi tersebut secara tidak langsung dapat meningkatkan aktivitas gerakan otot yang berbanding lurus juga dengan peningkatan metabolisme sehingga berujung pada peningkatan suhu tubuh.

Hasil penelitian menunjukan bahwa sebelum diberikan nesting rerata saturasi oksigen responden sebesar $92 \%$. Kondisi ini menggambarkan bahwa responden memiliki saturasi oksigen yang normal. Hal ini dikarenakan bayi baru lahir mengandung $80 \%$ kadar hemoglobin janin (Wong,et all, 2009). Hal ini membuat saturasi oksigen neonatus tergolong normal. Kondisi ini bertahan sampai akhir bulan pertama kehidupan. Hasil penelitian ini didukung berdasarkan data dimana rata - rata usia responden masih dibawah satu minggu.

Saturasi oksigen didefinisikan sebagai prosentase jumlah hemoglobin yang teroksigenasi dalam darah, sekitar 97\% oksigen yang ditransportasikan ke dalam aliran darah berkaitan dengan hemoglobin di dalam sel darah merah dan $3 \%$ lainnya larut dalam plasma. Hemoglobin yang mengikat jumlah maksimum oksigen dalam setiap molekulnya disebut kondisi tersaturasi (Hockenberry \& Wilson, 2007).

Sedangkan rerata saturasi oksigen responden setelah penggunaan nesting yaitu sebesar $95 \%$. Artinya terdapat peningkatan sebesar $3 \%$. Kondisi ini menunjukan kadar oksigen yang tinggi didalam darah. Peneliti berpendapat hal ini dikarenakan rerata responden masih berusia sangat muda (kurang dari satu minggu), sehingga akumulasi hemoglobin yang tinggi menjadi kunci masih tingginya saturasi oksigen. Faktor lainnya adalah intake nutrisi yang didapatkan oleh responden seperti ASI maupun PASI bisa meningkatkan kadar hemoglobin sehingga pada akhirnya bisa meningkatkan saturasi oksigen. Intake nutrisi yang baik tentu saja dipengaruhi oleh lingkungan yang nyaman dimana salah satunya didukung oleh penggunaan nesting. Hal ini didukung oleh penelitian Comaru dan Miura (2009), dikatakan bahwa penggunaan nesting mampu menurunkan stres pada bayi prematur sehingga menurunkan metabolisme tubuh dan berdampak pada peningkatan saturasi 
oksigen. Meskipun demikian, kisaran normal saturasi oksigen pada neonatus perlu dipelihara pada kisaran $90-92 \%$ (Merenstein \& Gardner, 2002). Dalam penelitian ini bisa disimpulkan terjadinya peningkatan saturasi oksigen dipengaruhi oleh menurunnya aktivitas metabolisme karena rasa nyaman dari penggunaan nesting serta masih adanya sisa fase akumulasi hemoglobin sampai dengan adanya pemberian intake nutrisi yang didapat oleh responden.

Hasil penelitian menunjukan rerata frekuensi nadi sebelum penggunaan nesting yaitu 130x/menit. Batasan normal frekuensi nadi pada neonatus adalah $120-160$ $\mathrm{x} /$ menit (Merenstein \& Gardner, 2002). Kondisi ini menggambarkan frekuensi nadi responden berada dalam batasan normal. Hal ini dikarenakan rerata suhu tubuh responden mengalami hipotermi. Kondisi ini mengakibatkan tubuh merespon dengan meningkatkan kerja jantung untuk meningkatkan metabolisme sel serta kebutuhan oksigen. Adanya peningkatan kontraktilitis jantung berbanding lurus dengan peningkatan frekuensi nadi.

Sedangkan setelah penggunaan nesting, rerata frekuensi nadi responden menjadi $143 \mathrm{x} /$ menit. Artinya terdapat peningkatan rerata frekuensi nadi pada responden. Kondisi ini menunjukan frekuensi nadi responden masih berada dalam kisaran normal. Berdasarkan hasil observasi peneliti, adanya peningkatan frekuensi nadi pada kelompok ini satu diantaranya karena masih tingginya stressor lingkungan seperti kebisingan ruangan, beberapa prosedur medis dan tindakan keperawatan. Hasil analisis ini, tidak menutup kemungkinan kondisi ini menjadi sumber stres yang dapat meningkatkan saraf simpatis sehingga meningkatkan kontraktilitas jantung. Kondisi ini dapat meningkatkan frekuensi nadi responden. Meskipun demikian, penggunaan nesting pada responden, mampu meminimalkan stressor akibat kondisi yang disebutkan diatas. Hal ini terbukti dengan masih normalnya rerata frekuensi nadi responden meskipun ada sedikit peningkatan.

\section{Pengaruh Nesting Terhadap Perubahan Suhu Tubuh BBLR}

Hasil penelitian menunjukan ada perbedaan suhu tubuh BBLR sebelum dan sesudah penggunaan nesting. Artinya adanya pengaruh nesting terhadap perubahan suhu tubuh BBLR. Hasil penelitian menunjukan terjadi peningkatan suhu $0,5^{\circ} \mathrm{C}$ pada BBLR setelah 30 menit penggunaan nesting. Hasil penelitian juga menunjukan rerata suhu tubuh $36,8^{\circ} \mathrm{C}$ setelah penggunaan nesting dari sebelumnya hanya $36,3^{\circ} \mathrm{C}$. Hasil ini menunjukan bahwa penggunaan nesting efektif untuk meningkatkan suhu tubuh BBLR berada dalam kisaran suhu tubuh normal yaitu $36,5^{\circ} \mathrm{C}-37,2^{\circ} \mathrm{C}$. Hasil penelitian ini didukung oleh penelitian Poulose (2015), dalam penelitiannya yang dilakukan pada 60 responden yang terbagi menjadi 30 responden kasus dan 30 responden kontrol. Hasil penelitiannya membuktikan bahwa BBLR yang diberikan nesting selama 9 jam per hari selama 5 hari menunjukan bahwa postur, kenyamanan dan parameter fisiologi (suhu aksila, nadi dan respirasi) menunjukan nilai yang signifikan yaitu $\mathrm{t}=12,64$ yang berarti bahwa studi membuktikan nesting pada BBLR efektif dalam memperbaiki pertumbuhan, mununjukan kenyamanan serta menstabilkan parameter fisiologis seperti suhu, nadi dan pernapasan BBLR.

Adanya pengaruh nesting terhadap suhu tubuh BBLR berdasarkan asumsi peneliti karena nesting mampu memberikan kenyamanan pada bayi. Saat diberikan nesting, bayi BBLR mampu melakukan posisi fleksi. Hal ini dijelaskan oleh Wong et al (2009), dimana posisi ini mendukung regulasi diri dan meningkatkan aktivitas tangan ke mulut dan tangan menggenggam. Dalam Bobak, lowdemik dan Jensen (2005), diduga posisi fleksi pada bayi baru lahir berfungsi sebagai sistem pengaman untuk mencegah kehilangan panas karena sikap ini mengurangi pemajanan permukaan 
tubuh pada suhu lingkungan. Berdasarkan penjelasan dari beberapa sumber, penulis menyimpulkan bahwa penggunaan nesting efektif untuk membuat bayi bersikap fleksi yang pada akhirnya bisa meningkatkan kenyamanan serta meminimalkan kehilangan panas akibat keterpaparan dengan suhu lingkungan luar.

\section{Pengaruh Nesting Terhadap Perubahan Saturasi Oksigen BBLR}

Hasil penelitian menunjukan ada perbedaan saturasi oksigen BBLR sebelum dan sesudah penggunaan nesting. Artinya adanya pengaruh nesting terhadap perubahan saturasi oksigen BBLR. Hasil penelitian menunjukan terjadi peningkatan saturasi oksigen pada BBLR setelah 30 menit penggunaan nesting. Hasil penelitian juga menunjukan rerata saturasi oksigen 95\% setelah penggunaan nesting dari sebelumnya hanya $92 \%$. Hasil ini menunjukan bahwa penggunaan nesting efektif untuk meningkatkan saturasi oksigen. Mesipun ada peningkatan, namun saturasi oksigen pada bayi baru lahir perlu dipertahankan pada kisaran $90-92 \%$.

Peneliti berasumsi adanya peningkatan saturasi oksigen pada kasus ini karena usia bayi yang relatif muda dibawah satu bulan berhubungan dengan masih adanya sisa fase akumulasi hemoglobin sampai dengan adanya pemberian intake nutrisi yang didapat oleh responden. Selain itu, faktor kenyamanan yang dialami bayi mampu menurunkan metabolisme tubuh yang pada akhirnya bisa meningkatkan saturasi oksigen. Hemoglobin berperan dalam mengikat oksigen dalam setiap molekulnya. Oleh sebab itu, bila kadar hemoglobin dalam darah kurang akan mempengaruhi saturasi oksigen dalam tubuh.

Hasil penelitian ini didukung oleh Zen (2017), menjelaskan bahwa ada pengaruh nesting terhadap peningkatan saturasi oksigen pada bayi prematur dengan $\mathrm{p}$ value $=0,000$. Hasil penelitian lainnya oleh Rahmawaty, Prawesti \& Fatimah
(2017), menjelaskan bahwa ada pengaruh yang bermakna nesting terhadap saturasi oksigen dengan $\mathrm{p}$ value $=0,000$. Hasil penelitian serupa juga dilakukan oleh Bayuningsih (2011), menjelaskan bahwa terdapat perbedaan bermakna saturasi oksigen sebelum dan sesudah penggunaan nesting pada bayi prematur dengan $p$ value $=0,001$. Berdasarkan beberapa hasil penelitian sejenis, penulis menyimpulkan bahwa terdapat pengaruh nesting terhadap perubahan saturasi oksigen pada bayi BBLR. Adanya peningkatan saturasi oksigen pada BBLR dikarenakan saat penggunaan nesting, bayi dalam keadaan nyaman karena bersikap fleksi sehingga mengurangsi stres dan menurunkan metabolisme. Hal ini didukung oleh Nair, Gipta \& Jatana (2003), menjelaskan bahwa posisi terbaik pada bayi prematur adalah melakukan posisi fleksi karena akan menurunkan metabolisme dalam tubuh bayi sehingga meningkatkan saturasi oksigen.

\section{Pengaruh Nesting Terhadap Perubahan Frekuensi Nadi BBLR}

Hasil penelitian menunjukan ada perbedaan frekuensi nadi BBLR sebelum dan sesudah penggunaan nesting. Artinya adanya pengaruh nesting terhadap perubahan frekuensi nadi BBLR. Hasil penelitian menunjukan terjadi peningkatan frekuensi nadi pada BBLR setelah 30 menit penggunaan nesting. Hasil penelitian juga menunjukan rerata frekuensi nadi 143 $\mathrm{x} /$ menit setelah penggunaan nesting dari sebelumnya hanya $130 \mathrm{x} / \mathrm{menit}$. Hasil penelitian menunjukan adanya peningkatan frekuensi nadi setelah penggunaan nesting. Meskipun ada peningkatan, namun rerata frekuensi nadi masih dalam batasan normal. Batasan normal frekuensi nadi pada neonatus adalah $120-160 \quad$ x/menit (Merenstein \& Gardner, 2002).

Berdasarkan hasil observasi peneliti, meskipun bayi mendapatkan nesting namun disekitar lingkungan bayi masih ada stimulus yang menjadi stresor sepertihalnya kebisingan ruangan, beberapa prosedur 
medis dan tindakan keperawatan. Hasil analisis ini, tidak menutup kemungkinan kondisi ini menjadi sumber stres yang dapat meningkatkan saraf simpatis sehingga meningkatkan kontraktilitas jantung sehingga frekuensi nadipun akan meningkat. Meskipun demikian, secara statistik hasil penelitian membuktikan bahwa ada pengaruh nesting terhadap frekunesi nadi BBLR dengan $\mathrm{p}$ value = 0,000 . Hasil penelitian ini bertolak belakang dengan penelitian Zen (2017) dan Bayuningsih (2011), menjelaskan bahwa tidak ada pengaruh nesting terhadap frekunesi nadi BBLR dengan masing masing $p$ value $=0,601$ dan 0,087 . Adanya perbedaan hasil dengan penelitian sebelumnya, penulis berasumsi karena hal ini dipengaruhi oleh jumlah responden serta karakteristik dari responden. Pada penelitian sebelumnya jumlah responden lebih sedikit dibandingkan dengan hasil penelitian peneliti, sehingga peneliti berpendapat jumlah responden yang lebih besar maka hasil penelitianpun juga akan lebih representatif. Perbedaan lainnya dimana pada penelitian sebelumnya tidak mempertimbangkan berat badan responden sedangkan pada penelitian ini berat badan menjadi salah satu kriteria inklusi. Berdasarkan adanya beberapa perbedaan diatas, bisa menjadi jawaban dari perbedaan dengan hasil penelitian sebelumnya. Oleh karenanya, penelitian lanjutan diharapkan bisa melakukan homogenitas terhadap kriteria sampel yang akan diteliti selanjutnya.

\section{Simpulan}

1. Rerata suhu tubuh, saturasi oksigen dan frekuensi nadi BBLR ada peningkatan setelah penggunaan nesting

2. Terdapat perbedaan suhu tubuh BBLR sebelum dan sesudah penggunaan nesting dengan $\mathrm{p}$ value $=0,000$, atau dengan kata lain terdapat pengaruh penggunaan nesting terhadap suhu tubuh BBLR
3. Terdapat perbedaan saturasi oksigen BBLR sebelum dan sesudah penggunaan nesting dengan $\mathrm{p}$ value $=$ 0,000 , atau dengan kata lain terdapat pengaruh penggunaan nesting terhadap saturasi oksigen BBLR

4. Terdapat perbedaan frekuensi nadi BBLR sebelum dan sesudah penggunaan nesting dengan $\mathrm{p}$ value $=$ 0,000 , atau dengan kata lain terdapat pengaruh penggunaan nesting terhadap frekuensi nadi BBLR

\section{Saran}

1. Disarankan bagi pihak RSD Gunung Jati kota Cirebon, khususnya ruangan perinatologi untuk membuat SOP tentang penggunaan nesting dengan memasukan pertimbangan hasil penelitian sejenis serta memberikan kesempatan bagi perawat untuk mengikuti kegiatan pelatihan developmental care untuk meningkatkan pengetahuan dan keterampilan perawat dalam menangani masalah keperawatan bayi dengan BBLR maupun prematur.

2. Disarankan bagi perawat yang sudah terlatih, untuk melanjutkan penggunaan nesting diruangan agar pemulihan dan kestabilan tanda vital bayi BBLR bisa dilaksanakan dengan tepat dan cepat

3. Disarankan bagi peneliti selanjutnya untuk menggali variabel lain seperti pengaruh nesting terhadap perubahan berat badan, reflek sucking dan hormon kortisol dengan menggunakan desain penelitian dan uji yang berbeda serta menggunakan jumlah sampel yang lebih banyak.

\section{Daftar Pustaka}

Altimier, L. (2011). Mother and Child Integrative Developmental Care Model: A Simple Approach to a Complex Population. Newborn \& Infant, Nursing Review, 11 (3),105108. 
Bayuningsih, R. (2011). Efektifitas penggunaan nesting dan posisi prone pada bayi premature terhadap saturas ioksigen dan frekuensi nadi di Rumah Sakit Umum Daerah Kota Bekasi. Tesis. Tidak Dipublikasikan. Depok : Universitas Indonesia.

Berman, A., Snyder, S., \& Kozier B. (2009). Praktik keperawatan klinis. Terjemahan. Jakarta: EGC

Bobak ; Lowdermilk ; Jensen. (2005). Buku Ajar Keperawatan Maternitas. Edisi 4. Jakarta : EGC

Comaru, T., \& Miura, E. (2009). Posture support improves distress and pain during diaper change in preterm infant. Journal of perinatology, 504-507

Deswita. (2010). Pengaruh perawatan metode kangruru terhadap respon fisiologis bayi premature dan kepercayaan diri ibu dalam merawat bayi di dua rumah sakit di Jakarta, diunduh pada tanggal 10 Juli 2018 dari www.lib.ui.ac.id.

Gibbins, S., Hoath, SB., Couglin, M., Gibbins A., \& Franck L. (2008). The universe of develompmental care: A new conceptua; mode for application in the neonatal intensive care unit. Advance in Neonatal Care. 8(3).141147.

Hockenberry, M.J, \& Wilson, D. (2007). Wong's : Nursing Care of Infants and Children. St : Louis : Mosby

Hockenberry, MJ.,\& Wilson, D. (2009). Wong's essential of pediatric nursing. $8^{\text {th }}$ Edition. St. Louis. Mosby. Inc.

Mac Gregor, J.(2008). Introduction to the antomy and physiology of children: A guide for students of nursing, child care and health. $2^{\text {nd }}$ Edition. New York: Routledge.

Merrenstein, G.B., \& Gardner, S.L. (2002). Handbook of neonatal intensive care. Missouri : Mosby, Inc.

Miller, S.S., Lee, H.C., \& Gould,J.B. (2011). Hypotermia in very low birth weigh infant: distribution,risk factors and outcomes. $\underline{J \text { Perinatol. }}$
Mitchell, Gemma L, et al. (2012). Parental influences on children's eating behaviour and characteristics of successful parent-focussed interventions. Appetite 60 (85-94).

Nair, Gupta, G., \& Jatana. (2003). NICU Environment : Can we be ignorant. MJAFI, 93-95

Notoatmodjo, S. 2010. Metodologi Penelitian Kesehatan. Jakarta. PT. Rineka Cipta.

Perinasia. (2003). Perawatan bayi berat lahir rendah dengan metode kanguru. Jakarta : Perinasia.

Poulose, R., Babu, M., \& Rastogi, S. (2015). Effect of nesting on posture discomfort and physiological parameter of low birth weight infants. IOSR Journal of nursing and health science, $46-50$

Rahmawaty, S; Prawesty,A; Fatimah, S. (2017). Pengaruh nesting terhadap saturasi oksigen dan berat badan pada bayi prematur di ruang perinatologi RSUP Dr Hasan Sadikin Bandung. Jurnal Keperawatan Aisyiyah.4 (2): 18

Sloan, N.L., et al. (2008). Communitybased kangaroo mother care to prevent neonatal and infant mortality: A randomized controlled cluster trial. Pediatrics, 121(5), 1047-1059

Syahreni, E.(2010). Tesis : Pengaturan pengaruh stimulus sensoris terhadap respon fisiologis dan perilaku BBLR di RSUPN Dr. Ciptomangunkusumo. Tidak dipublikasikan.Depok : Universitas Indonesia

Wilkinson, J.M dan Green, C.J. (2012). Rencana Asuhan Keperawatan. Alih Bahasa: Monica,dkk. Jakarta: EGC.

Zen, Nurbaeti Dini. (2017). Pengaruh nesting terhadap perubahan fisiologis dan perilaku bayi prematur di perinatologi Rumah Sakit Umum Daerah Tasikmalaya. Jurnal Kesehatan Bakti Tunas Husada. Volume 17 (2). 